\title{
Natural Beauty Is Worth Saving
}

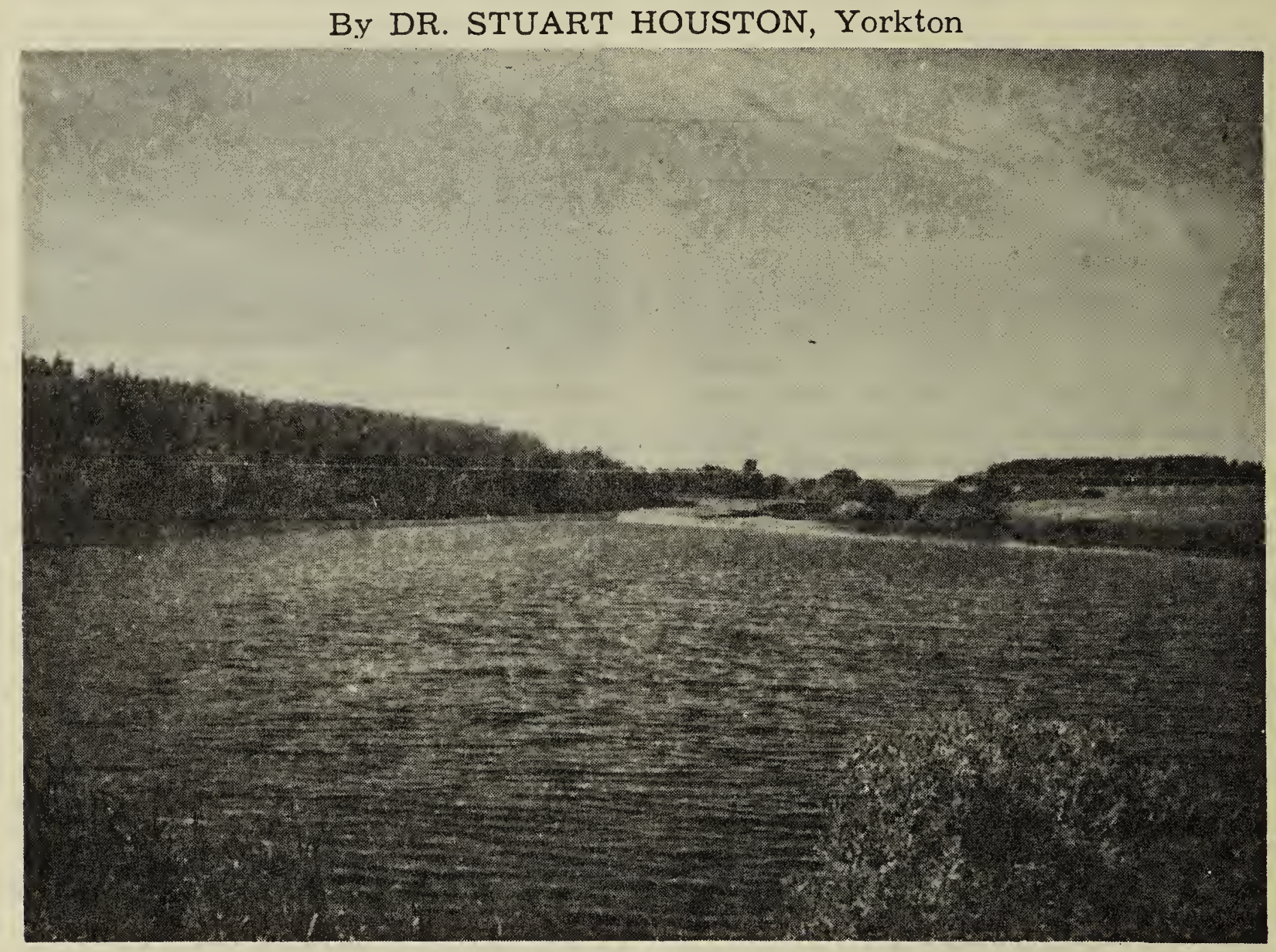

PRAIRIE SLOUGH FOUR MILES SOUTH OF YORKTON

Photo from kodachrome by Dr. Stuart Houston

In Jubilee Year we think back over the changes of the last fifty years. Might it not also be profitable to think ahead to the next fifty years? Can the nature lover do so, however, without uneasy qualms?

Population pressures are increasing, transportation now leaves few places inaccessible, the almighty dollar remains the chief concern of most people. Everyone shrugs their shoulders and says "You can't hold back progress." With this they justify, without thinking, both necessary development and stupid wasteful destruction. "Progress" to many is a sacred goddess and with this one word they feel they have justified their mistakes. They forget that progress can be backwards as well as forwards.

One sees evidence on every hand. When a farmer clears land, so often he clears around the margins of the little sloughs, clears the willows from the banks of the little streams, and fails to leave any windbreak anywhere. Often the value of the land is thus decreased - the dry winds blow away the valuable topsoil, the floods wash it down the river. There is no cover left for the Sharp-tailed Grouse, and many other birds and animals. The beauty is gone.

No one seems to notice what damage has been done until it is too late. The man behind the bulldozer usually uproots every tree and shrub in sight, and seems to delight in leaving nothing standing. What about future generations - what kind of country are we leaving our grandchildren?

This would be a good time for the Natural History Society, and the Fish \& Game Leagues to launch a campaign to save our natural trees and shrubs. After all, the Creator placed them here and $\mathrm{He}$ must have thought them suitable. We must get busy now - soon it will be too late. 